Nov 2018 a Fev $2019-$ v.9 - n.1

\title{
Perfil socioeconômico e práticas agrícolas de agricultores familiares no município de Chapadinha (MA)
}

Ao longo do processo de produção de hortaliças, há diversos riscos de contaminação suscetíveis às culturas. $O$ objetivo dessa pesquisa foi analisar as técnicas de produção de hortaliças e os riscos ocupacionais aos quais podem estar expostos os agricultores da Comunidade Kolping, de Chapadinha (MA) (COKC). Esta pesquisa baseia-se em um estudo de caso, em que os dados foram coletados através de aplicação de questionários e interpretados por estatística descritiva. De acordo com as informações levantadas, a comunidade é constituída, predominantemente, por mulheres, que correspondem a $89 \%$ dos entrevistados. No que tange ao sistema de produção, é caracterizado como de baixa produtividade, sem uso de tecnologias. A análise e caracterização do sistema de produção adotado pelos agricultores da COKC permitiram compreender que a eficiência da atividade agrícola dos membros é comprometida em função de fatores limitantes, como gestão da produção ineficiente, ausência de articulação e falta de assistência técnica. Nesse sentido, as recomendações sugeridas aos membros da COKC se pautaram na valorização do trabalho em equipe e na adoção de boas práticas agrícolas.

Palavras-chave: Segurança Alimentar; Saúde Ocupacional; Resíduos Sólidos; Administração Rural.

\section{Socioeconomic profile and agricultural practices of family farmers in the municipality of Chapadinha (MA)}

Throughout the vegetable production process, there are several risks of contamination susceptible to crops. The objective of this research was to analyze the vegetable production techniques and the occupational risks to which farmers of the Kolping Community of Chapadinha (MA) (COKC) may be exposed. This research is based on a case study, in which data were collected through questionnaires and interpreted by descriptive statistics. According to the information collected, the community is predominantly made up of women, which correspond to $89 \%$ of respondents. Regarding the production system, it is characterized as low productivity, without the use of technologies. The analysis and characterization of the production system adopted by COKC farmers allowed us to understand that the efficiency of the members' agricultural activity is compromised due to limiting factors, such as inefficient production management, lack of articulation and lack of technical assistance. In this sense, the recommendations suggested to COKC members were based on valuing teamwork and adopting good agricultural practices.

Keywords: Food safety; Occupational health; Solid waste; Rural Administration.

Topic: Extensão e Desenvolvimento Rural

Reviewed anonymously in the process of blind peer
Received: 06/01/2019

Approved: 07/02/2019
José Bonifácio Martins Filho (iD)

Universidade Federal do Maranhão, Brasil

http://lattes.cnpq.br/4819207696239648

http://orcid.org/0000-0002-9170-5350

boni.martins@outlook.com

Klara Cunha de Meneses

Universidade Federal do Maranhão, Brasil

http://lattes.cnpq.br/9688947861521570

klaramenesesc@hotmail.com

\section{Renata Santos Coutinho}

Universidade Federal do Maranhão, Brasil

http://lattes.cnpq.br/1970459593786308

renatas.coutinho@hotmail.com

\author{
Lindykeila Ferreira Reinaldo \\ Universidade Federal do Maranhão, Brasi \\ http://lattes.cnpq.br/9219094852756047 \\ lindykeila@hotmail.com \\ Isabela Cristina Gomes Pires (iD \\ Universidade de São Paulo, Brasil \\ http://lattes.cnpq.br/3393211586560026 \\ http://orcid.org/0000-0002-9055-9435 \\ icgpires@yahoo.com.br \\ Gregori da Encarnação Ferrão (iD \\ Universidade Federal do Maranhão, Brasi \\ http://lattes.cnpq.br/4627304990166302 \\ http://orcid.org/0000-0002-1740-6723 \\ gregoriferrao@yahoo.com.br
}

Referencing this:

MARTINS FILHO, J. B.; MENESES, K. C.; COUTINHO, R. S.; REINALDO, L. F.; PIRES, I. C. G.; FERRÃO, G. E.. Perfil socioeconômico e práticas agrícolas de agricultores familiares no município de Chapadinha (MA). Natural Resources, v.9, n.1, p.1-10, 2019. DOI:

http://doi.org/10.6008/CBPC2237-9290.2019.001.0001

DOI: 10.6008/CBPC2237-9290.2019.001.0001 


\section{INTRODUÇÃO}

A agricultura familiar no Brasil é responsável pelo fornecimento de alimentos para uma significativa parcela da população do país (ALVES et al., 2011). No entanto, os agricultores familiares possuem fraquezas que são entraves agressivos contra produtividade de suas propriedades, e entre elas se destacam a baixa escolaridade, pouca organização, ausência de gestão produtiva e dificuldade em atender a exigências sanitárias e ambientais vigentes (CARVALHO et al., 2015; IBGE, 2006).

Os agricultores familiares possuem uma afinidade coerente com a produção de hortaliças, pois para que se obtenham resultados economicamente viáveis, as hortaliças não necessitam de grandes extensões de terras, como outras produções agrícolas e também não exigem muito conhecimento técnico e nem elevado investimento inicial (FAULIN et al., 2003). Ao longo do processo de produção de hortaliças, há diversos riscos de contaminação física, química e/ou biológica susceptíveis as culturas caso não sejam adotadas boas práticas que assegurem a qualidade e segurança dos alimentos produzidos (MATTOS et al., 2009).

O crescente interesse por uma alimentação saudável surge em parte da necessidade de conhecer as condições em que foram produzidos os alimentos que estão diariamente na mesa dos brasileiros. Assim, a adoção das Boas Práticas Agrícolas (BPAs) são fundamentais na produção de alimentos, e abrangem desde a escolha do local para plantio até ao processamento na agroindústria incluindo a distribuição ao consumidor final (BRASIL, 2017).

A completa sanidade dos alimentos também deve estar aliada ao cumprimento de condições de trabalho salubres ao longo da cadeia produtiva de um determinado produto aos trabalhadores do segmento, preservando a segurança e saúde de quem produz e manipula alimentos (NEVES, 2005). Diante do exposto, o objetivo dessa pesquisa foi analisar as técnicas de produção de hortaliças e os riscos ocupacionais os quais podem estar expostos os agricultores da Comunidade Kolping de Chapadinha (MA) (COKC).

\section{METODOLOGIA}

O ambiente da presente pesquisa foi a Comunidade Kolping, localizada no município de Chapadinha (MA) que possui uma área de $3 \mathrm{mil} \mathrm{km}^{2}$, uma população de aproximadamente 78 mil habitantes e uma densidade demográfica de 23 habitantes por km² (IBGE, 2015). Esta comunidade situa-se mais precisamente no Bairro Areal, distante cerca de $8 \mathrm{~km}$ do centro do referido município, nas seguintes coordenadas latitude 03ㅇ 44' 30" S e longitude: 43ㅇ 21' 37" W. Chapadinha possui uma temperatura média anual superior a $27^{\circ} \mathrm{C}$ e precipitação pluvial média anual de $1.835 \mathrm{~mm}$, a classificação climática do município de acordo com a classificação de Köppen, é do tipo tropical quente e úmido (Aw) (PASSOS et al., 2016).

A comunidade possui uma área total de $11.040 \mathrm{~m}^{2}$ (1,104 ha), desse total aproximadamente $1.076 \mathrm{~m}^{2}$ é reservado para plantio, realizado em canteiros de tamanhos não uniformes, ou seja, mais de $90 \%$ da área está ociosa. A organização possui uma sede dotada de um poço artesiano de profundidade de 126 metros, caixa d'água com capacidade de $5 \mathrm{~m}^{3}$ e espaço reservado para beneficiamento da produção. 
O presente trabalho baseia-se em um estudo de caso, em que os dados foram coletados através de aplicação de questionários aos 9 membros (100\% dos membros atuais da organização) no mês de outubro de 2017, com o objetivo de conhecer as variáveis que expressam as condições socioeconômicas e as técnicas de produção adotadas pelos agricultores da COKC.

O questionário é composto por 25 perguntas, 6 objetivas e 19 abertas. Foi utilizado o software Excel para o agrupamento e compilação dos dados coletados, e a interpretação foi realizada por análise estatística descritiva. As medidas corretivas sugeridas para comunidade foram baseadas em revisões bibliográficas afim de eliminar problemas relacionados às práticas agrícolas dos horticultores bem como sua segurança e saúde no trabalho.

\section{RESULTADOS E DISCUSSÃO}

\section{Aspectos organizacionais}

A COKC foi fundada em Chapadinha aos vinte seis de abril de mil novecentos e oitenta e seis, e faz parte da Obra Kolping do Brasil, que pode ser conceituada como um movimento social ligado à igreja católica com a missão de 'Transformar as realidades sociais no exercício da cidadania através do desenvolvimento profissional, ambiental, cultural, religioso e comunitário'. No município, a comunidade conta com a participação de 9 membros que trabalham com a produção de hortaliças (coentro, cebolinha, couve-folha e pimenta de cheiro) em baixa escala para comercialização em feira livre no mercado municipal.

Os membros da COCK podem cultivar nos canteiros e para isso devem pagar uma taxa de dez reais por mês para utilizar a área com direito ao uso da energia e água para irrigar suas plantações. Embora trabalhem no mesmo local, cada membro deve ser responsável pela compra de seus próprios insumos e comercializar sua produção.

Os recursos financeiros obtidos pela COKC através de seus membros são para arcar com o único custo variável mensal da organização, o gasto com energia elétrica, pois utilizam um conjunto motobomba para captar água do poço para irrigar as culturas. Entretanto, a comunidade realiza, quando necessário, eventos beneficentes, a fim de aumentar a receita e suprir algum problema de interesse coletivo como reformas no prédio sede da organização. Os integrantes da organização se reúnem mensalmente, sempre ao primeiro domingo de cada mês com objetivo de deliberarem sobre assuntos pertinentes aos mesmos, sendo as reuniões conduzidas pela presidente da COKC.

\section{Perfil socioeconômico}

A partir da análise dos dados sobre o gênero, constatou-se que a COKC é constituída, predominantemente, por mulheres (correspondem a $89 \%$ dos entrevistados) com ocupação de donas do lar, e a maioria (45\%) dos membros possui ensino fundamental incompleto (tabela 1), nível inferior ao grau de escolaridade de agricultores familiares da Cooperativa de Comercialização dos Produtos da Agroindústria 
Familiar Integrada de Francisco Beltrão no estado no Paraná, na qual grande parte dos cooperados (92\%) possuíam ensino fundamental completo (ALVES et al., 2010).

Tabela 1: Aspectos sociais dos membros da comunidade Kolping de Chapadinha (MA).

\begin{tabular}{|l|l|l|}
\hline \multicolumn{2}{|c|}{ Variável } & 11 \\
\hline Sexo & Masculino & 89 \\
\hline Faixa etária & Feminino & 33 \\
& Menos de 40 anos & 67 \\
\hline Escolaridade & Mais de 40 anos & 11 \\
& Ensino médio completo & 45 \\
& Ensino fundamental incompleto & 22 \\
& Ensino fundamental completo & 22 \\
\hline
\end{tabular}

O estado civil dos agricultores da COKC é de $67 \%$ casados e 33\% união estável. A maioria (67\%) declarou-se parda, seguidos de $22 \%$ declarados como negros e $11 \%$ como brancos. Mais da metade dos membros atuais (56\%) trabalham na COKC há 3 anos e $22 \%$ trabalham a mais de 20 anos. A renda oriunda da atividade desenvolvida por eles não chega a atingir um salário mínimo vigente no Brasil $(R \$ 937,00)$, em função disso, $56 \%$ afirmam que o trabalho na horticultura não é sua ocupação principal, sendo que $100 \%$ dos membros do sexo feminino também executam atividades domésticas em suas casas. Estes resultados inserem-se nas abordagens do censo agropecuário de 2006 que relata o valor da renda líquida mensal de agricultores das classes econômicas D e E com um valor inferior ao salário mínimo (IBGE, 2006).

De acordo com as informações levantadas, a organização recebeu orientação técnica durante a implantação da comunidade no município, porém, atualmente, a COKC não contrata assistência técnica ou gerencial continuada para seus agricultores, eles trabalham sem planejamento e segundo suas próprias percepções sobre a horticultura. $\mathrm{O}$ desamparo do setor agropecuário, no que se refere à assistência técnica é comum no Brasil, pois mais de 4 milhões de estabelecimentos de produção rural não recebem ou não contratam orientação técnica, destes, os agricultores familiares que não recebem assistência técnica e extensão rural possuem uma renda média de cerca três vezes menor que os agricultores familiares atendidos por técnicos (IBGE, 2006). Tais dados demonstram que o acesso à informação é um fator significativo na alavancagem dos resultados financeiros de empreendimentos rurais.

\section{Caracterização do sistema de produção}

As culturas produzidas pelos agricultores da COCK são coentro (Coriandrumsativum), cebolinha (AlliumFistolossum), couve-folha (Brassicaoleracea) e pimenta de cheiro (Capsicumchinesen). A caracterização de um sistema de produção implica além de conhecer as técnicas adotadas por um agricultor, buscar relacioná-las com os recursos de que dispõem o trabalhador, as condições ambientais nas quais trabalha e seu perfil socioeconômico (GARCIA FILHO, 1999).

O sistema de produção dos horticultores da COKC está esquematizado na figura 1, o qual caracterizase de baixa produtividade justificado pelas eventuais perdas integrais dos canteiros por pragas ou por queimaduras do sol, sem uso de tecnologias e apresenta como técnicas de manejo o preparo do solo e irrigação de maneira rudimentar. 
Preparo do solo/plantio $\Rightarrow$ Irrigação $\Rightarrow$ Controle de pragas

Figura 1: Fluxograma do sistema de produção dos agricultores da COKC.

A aquisição de insumos é realizada somente quando necessária por cada agricultor e os principais fornecedores são os estabelecimentos agropecuários varejistas de Chapadinha, com exceção do esterco que é adquirido com produtores de caprinos também do próprio município e as sementes de coentro que são compradas de Tianguá (CE). A etapa de preparo do solo e plantio que envolvem também outros tratos culturais (adubação e capina) são realizados individual e manualmente ou com enxada. Há somente adubação de pré-plantio com a utilização de esterco de caprino e ou substrato de babaçu, após o plantio não é realizado nenhuma adubação de crescimento, apenas capinas quando necessário.

As hortaliças, produzidas pelos agricultores da COKC, não são cultivadas em ambiente protegido, estão sujeitas a eventos climáticos extremos constantemente, pois a exposição à radiação solar intensa resulta em queimaduras nas folhas e as chuvas intensas de verão podem causar danos físicos nas plantações, tais intempéries influenciam diretamente na produtividade.

O cultivo protegido é responsável por garantir a regularidade de oferta de alimentos em diferentes épocas do ano, é amplamente utilizado e recomendado para hortaliças, haja visto que são culturas bastante sensíveis (EMBRAPA, 2015). Grande et al. (2003) observou a tendência de produtores de Uberlândia (MG) em investir no segmento de cultivo protegido afim de melhorar a qualidade dos vegetais, manter a produção em diferentes estações do ano e assim conseguir melhores preços. A organização não possui sistema de irrigação adequado, a água é captada do poço pela bomba, e armazenada na caixa d'água que por gravidade transporta a água para anéis de concreto.

Os agricultores regam as culturas com regadores e baldes diariamente, em função disso e de acordo com a perspectiva de $67 \%$ dos entrevistados, a recorrência de dores na coluna e/ou em membros inferiores e superiores possui relação com essa atividade de irrigação manual. O risco ergonômico (físico) é evidenciado pelo transporte de cargas com excesso de peso (15 a 20 litros de água) pela necessidade de irrigar os canteiros e na fase de colheita pelas posturas inadequadas e posições agachada (cócoras, sentados ou ajoelhados no chão).

As análises físico-químicas da água (tabela 2) usada para irrigação, que também é utilizada por 100\% dos membros da COKC para consumo, demonstraram que alguns dos parâmetros físico-químicos analisados ( $\mathrm{pH}$, Salinidade, Condutividade Elétrica e Temperatura) apresentaram características divergentes em relação as recomendações para irrigação e para o consumo humano.

Tabela 2: Características físico-químicas d'água de irrigação da COKC.

\begin{tabular}{|l|l|l|l|}
\hline PH & Salinidade & Condutividade elétrica & Temperatura \\
\hline 4,60 & $273 \mathrm{ppm}$ & $508 \mu \mathrm{s} / \mathrm{cm}$ & $30,2^{\circ} \mathrm{C}$ \\
\hline
\end{tabular}

A água apresentou pH de 4,60 considerado ácido para consumo humano, haja visto que há recomendação de que, no sistema de distribuição, o pH da água deva ser mantido na faixa de 6,0 a 9,5 (BRASIL, 2000). Para Almeida (2010), o pH da água de irrigação fora da faixa de 6,5 a 8,4 (faixa considerada 
ideal) indica a presença de íons tóxicos e anormalidade na qualidade da água para irrigação o que pode causar danos a população microbiana do solo e ao sistema radicular das plantas.

As temperaturas ótimas para a água de irrigação situam-se entre $25^{\circ} \mathrm{C}$ e $30^{\circ} \mathrm{C}$, no entanto, de maneira geral a temperatura da água não implica em problemas em ambientes de climas tropicais, com exceções quando for excessivamente alta (EMBRAPA, 2017). A água da COKC pode ser classificada como água de salinidade média, e pode ser recomendada para irrigar plantas com moderada tolerância a sais (ALMEIDA, 2010).

Embora não haja sistema de irrigação específicos para hortaliças, é comum sugerir o método de irrigação localizada para esse tipo de cultura, pois ele apresenta as vantagens d'água ser aplicada diretamente no solo próximo das raízes, e implica em menos custos com mão de obra para a irrigação, sendo os principais sistemas indicados o gotejamento e a microaspersão (BERNARDO et al., 2006; SEBRAE, 2015).

$\mathrm{Na}$ etapa de controle de pragas, observou-se a falta de conhecimento dos horticultores quanto à utilização de equipamento de proteção individual (EPI), durante a aplicação de agroquímicos nas hortas, todos os trabalhadores já tiveram contato direto com substâncias tóxicas durante o processo de preparo das soluções a serem aplicadas nas culturas sem medida de segurança. O preparo é feito com a mistura do agrotóxico em baldes ou latões improvisados, sendo este um dos momentos de maior risco de contaminação para os agricultores, dada à exposição direta e a alta concentração do produto.

Os agricultores da COKC não monitoram a produtividade das culturas, portanto não possuem o controle e histórico da quantidade colhida por canteiro, no entanto, os membros afirmam que apesar das perdas, conseguem colher cerca de $70 \%$ da plantação por canteiro (quando não perdido em função de pragas ou queimaduras pelo sol). A colheita é realizada manualmente, o trabalho de pós-colheita compreende a retirada de folhas secas e lavagem das hortaliças com água oriunda de poço artesiano. 0 destino da produção é em sua maioria a comercialização no Mercado Municipal de Chapadinha, porém $89 \%$ dos agricultores da COCK afirmam que também consomem da sua produção eventualmente.

\section{Não conformidades}

Em algumas etapas do processo de produção foram observados procedimentos que expressam alguma inconformidade do trabalho realizado pelos agricultores da COKC com as recomendações sugeridas na Norma Regulamentadora 31 e/ou com Manual de Boas Práticas Agrícolas (tabela 3). As inadequações observadas na COKC expõem o agricultor, consumidor e o próprio alimento a perigos de dimensão química, física e biológica (tabela 4). O risco ergonômico (físico) manifestado nos horticultores pela sobrecarga muscular e posturas inadequadas durante a colheita, associado com o risco de contaminação química e biológica (agrotóxicos e microrganismos) pela não utilização de EPIs geram um ambiente ocupacional insalubre que pode comprometer significativamente a saúde dos horticultores da COKC.

Em função das hortaliças serem, conceitualmente, vegetais herbáceos nos quais uma ou mais partes são utilizadas como alimento na sua forma natural, isto é, podem ser consumidas cruas, implica no fato de que as mesmas podem ser canais de doenças transmitidas por alimentos (DTAs) e causar intoxicações 
alimentares em consumidores que adquirem o produto, desconhecendo os procedimentos utilizados para produzi-lo (ANVISA, 2002).

Tabela 3: Procedimentos adotados pelos agricultores da COKC.

\begin{tabular}{|l|l|l|l|}
\hline \multicolumn{1}{|c|}{$\begin{array}{c}\text { Etapa do sistema de } \\
\text { produção }\end{array}$} & \multicolumn{1}{|c|}{ Agricultores da COKC } & \multicolumn{1}{c|}{ Recomendação da NR31 } & \multicolumn{1}{c|}{$\begin{array}{c}\text { Recomendação do } \\
\text { Manual de BPA }\end{array}$} \\
\hline Aquisição de insumos & $\begin{array}{l}\text { Compra sem receituário } \\
\text { agronômico e sem instrução de } \\
\text { profissional habilitado }\end{array}$ & $\begin{array}{l}\text { Auxílio de um } \\
\text { profissional da área }\end{array}$ \\
\hline $\begin{array}{l}\text { Manuseio e aplicação } \\
\text { de agroquímicos }\end{array}$ & Sem uso de EPI & $\begin{array}{l}\text { Utilização de } \\
\text { EPI }\end{array}$ & $\begin{array}{l}\text { Utilização de } \\
\text { EPI }\end{array}$ \\
\hline $\begin{array}{l}\text { Destinação de } \\
\text { embalagem de } \\
\text { agroquímicos }\end{array}$ & Lixo convencional & Devolvidas ao fabricante & $\begin{array}{l}\text { Devolvidas ao } \\
\text { fabricante }\end{array}$ \\
\hline $\begin{array}{l}\text { Irrigação } \\
\text { Pós - colheita }\end{array}$ & $\begin{array}{l}\text { Irrigação manual com baldes e } \\
\text { regadores (sobrecarga muscular) }\end{array}$ & $\begin{array}{l}\text { Pausas para descanso para } \\
\text { atividade que exijam sobrecarga } \\
\text { muscular }\end{array}$ & - \\
\hline
\end{tabular}

Tabela 4: Perigos susceptíveis da ausência de BPAs aos alimentos, manipuladores e consumidores.

\begin{tabular}{|l|l|l|l|}
\hline PERIGOS & \multicolumn{1}{|c|}{ ALIMENTO } & \multicolumn{1}{|c|}{ AGRICULTOR } & \multicolumn{1}{c|}{ CONSUMIDOR } \\
\hline Químico & $\begin{array}{l}\text { Contaminação por resíduos de } \\
\text { agrotóxicos }\end{array}$ & Aspirar ou absorver substância tóxica & $\begin{array}{l}\text { Consumo de alimento } \\
\text { contaminado }\end{array}$ \\
\hline Físicos & $\begin{array}{l}\text { Lesão no vegetal e problemas no seu } \\
\text { desenvolvimento }\end{array}$ & $\begin{array}{l}\text { Causar lesões físicas no trabalhador rural } \\
\text { durante as práticas agrícolas }\end{array}$ & $\begin{array}{l}\text { Ferimento de boca e quebra } \\
\text { de dentes }\end{array}$ \\
\hline Biológico & $\begin{array}{l}\text { Doenças específicas, bacterianas, virais } \\
\text { e fúngicas na planta }\end{array}$ & $\begin{array}{l}\text { Infecção por bactéria, vírus, parasitos e } \\
\text { outros agentes biológicos }\end{array}$ & $\begin{array}{l}\text { Contato com agentes } \\
\text { patogênicos (DTAs) }\end{array}$ \\
\hline
\end{tabular}

Para diminuir ou eliminar a possibilidade de ocorrência dos danos ocupacionais apontados para os agricultores na tabela 4, torna-se necessário o entendimento de que a adoção de medidas de segurança não afetará somente a dimensão financeira, como também as exigências ambientais e sanitárias, configurandose como uma ótima estratégia de marketing para a promoção das hortaliças para os consumidores (SOUSA et al., 2010).

Os agricultores da COKC mencionaram a utilização do inseticida Barrage para o controle de pragas nas plantações, sendo aplicado no solo dos canteiros pelos horticultores com diferentes frequências e sem respeito ao período de carência. Para Santos et al. (2007), a utilização de inseticidas é indispensável para se obter bons resultados na agricultura, haja visto que os insetos são uma das pragas responsáveis pela diminuição na produtividade das lavouras. No entanto, de acordo com o Manual de BPA (2004), os agricultores devem utilizar apenas os agrotóxicos que são autorizados pelos órgãos nacionais competentes, respeitando as doses sugeridas no receituário agronômico e as recomendações do fabricante para cada cultura.

Segundo informações contidas na bula, o Barrage é uma substância facilmente emulsionável na água e contém 150 gramas de Alfa-ciano-3-fenoxibenzil-2,2-dimetil-3- (2,2-diclorovinil) - ciclopropanocarboxilato, (CYPERMETHRIN) por litro. Uma das precauções sugeridas pelo fabricante expressa explicitamente que o produto não deve ser aplicado em alimentos vegetais, pois trata-se de uma substância de uso estritamente veterinário. No entanto, os agricultores da COKC utilizam o Barrage com a justificativa de que o produto é eficaz no controle de pragas. 
O quadro que reflete o uso de agrotóxicos no nordeste brasileiro é significativamente próximo ao dos horticultores da COKC. Em estudos com horticultores do Município de Conceição do Jacuípe (BA), segundo maior polo de hortaliças do Estado da Bahia, Preza et al. (2012) constatou o uso de sete agrotóxicos não permitidos para uso em hortaliças.

No que tange ao descarte das embalagens, para 100\% dos horticultores da COKC, o destino é o lixo convencional. Araújo et al. (2001) também verificou a falta de preocupação dos produtores de hortaliças em polos de produção em São Luís (MA), e constatou que o descarte das embalagens em sua maioria (45\%) não obedecia às normas estabelecidas pela legislação vigente que preconiza que para embalagens de agrotóxicos miscíveis em água deve ser realizado o procedimento de tríplice lavagem ou método equivalente antes da devolução ao fabricante (ABNT, 1997; BRASIL, 2002).

\section{Administração da COKC}

A COKC caracteriza-se como um empreendimento rural tradicional, haja visto que os membros fazem uso de equipamentos agrícolas rudimentares e as decisões não são tomadas com base técnica ou científica (BATALHA, 2007). Os princípios organizacionais da comunidade (missão, visão e valores) não são claros para os membros, que apesar de serem uma organização dotada de personalidade jurídica, não trabalham de forma coletiva, e não há evidências da adoção das funções administrativas (Planejamento, Organização, Direção e Controle) de maneira racional, coerente e lógica.

Uma das etapas de fundamental importância para o processo produtivo é o planejamento. A gestão de uma empresa rural, assim como de outros segmentos exige que as escolhas e tomadas de decisões sejam racionais e busquem a eficiência dos fatores produtivos de maneira que o empreendimento alcance bons resultados (CONAB, 2010). No entanto, o planejamento da produção dos membros da COKC é extremamente básico, pois, embora sigam um processo sequencial de produção não adotam técnicas gerenciais ou qualquer princípio administrativo para nortear o trabalho desenvolvido.

O trabalho coletivo pode proporcionar o desenvolvimento necessário para a organização corrigir as inconformidades levantadas nesse estudo, porque entende-se que o associativismo e cooperativismos apresentam-se como estratégias para alcançar um equilíbrio eficiente e resultados econômicos satisfatórios em empreendimentos rurais de pequeno porte através do aproveitamento das potencialidades individuais, redução nos custos de insumos de produção e maiores chances de comercialização (BATALHA, 2007).

Normalmente, os pequenos produtores apresentam as mesmas dificuldades para conseguir um bom desempenho econômico, e a formação de associações pode ser considerada uma boa estratégia para o fortalecimento da agricultura familiar e simultaneamente, um mecanismo que assegura um melhor resultado para competir no mercado (BRASIL, 2012).

Ao contrário da dinâmica observada na COCK, para Chiavenato (2001), uma organização deve ser composta de integrantes que objetivam sobrepor suas próprias limitações individuais, e afirma que a dificuldade de alcançar objetivos isoladamente é a razão pela qual as pessoas se unem de forma organizada 
para atuar em conjunto eficazmente uns com outros. No entanto, essa estratégia não é adotada pelos os horticultores da comunidade em questão.

\section{Propostas de Medidas Corretivas e Ações Estratégicas}

Diante das inconformidades detectadas por esse estudo sugere-se aos membros da COKC como propostas de medidas corretivas: Aquisição de um sistema de irrigação localizada e assim evitar a sobrecarga de peso diariamente com a irrigação; Adquirir EPIs e realizar treinamentos; Suspender o uso do inseticida Barrage e consultar periodicamente um agrônomo para obtenção de receituário agronômico, com as considerações de produto mais indicado para determinada praga; e Higienizar adequadamente as hortaliças com substâncias para esse fim e em diluições recomendadas pelo fabricante no pós-colheita.

No que se refere a ações estratégicas, propõe-se: Unir esforços, afim de diminuir custos de produção e distribuir benefícios, aproveitando vantagens de se trabalhar coletivamente; Buscar assistência técnica e gerencial com foco de elevar a produtividade das hortas e desenvolver uma perspectiva empreendedora nos membros; e Realizar um planejamento da produção de maneira conjunta considerando fatores mercadológicos e sazonais do município, por meio de ferramentas administrativas.

\section{CONCLUSÕES}

A caracterização e análise do sistema de produção adotado pelos agricultores da COKC permitiu compreender que a eficiência da atividade agrícola dos membros é comprometida em função do conjunto de fatores limitantes como gestão da produção ineficiente, ausência de coordenação e falta de assistência técnica. Nesse sentido, considera-se primordial o rompimento da barreira do trabalho individual, afim de que a comunidade alcance um equilíbrio eficiente, construindo um ambiente de união benéfico entre membros com a possibilidade de melhoria da produtividade das hortaliças e adequação das técnicas de produção, a fim de evitar riscos à saúde dos horticultores da COCK.

\section{REFERÊNCIAS}

ABNT. Associação Brasileira de Normas Técnicas. Norma Brasileira 13968/1997: Embalagem rígida vazia de agrotóxico: Procedimentos de lavagem. Rio de Janeiro: ABNT, 1997.

ALMEIDA, O. A.. Qualidade da Água de Irrigação. Cruz das Almas: EMBRAPA, 2010.

ALVES, C. O. W.; SILOCHI, R. M. H. Q.. Caracterização dos agricultores familiares de frutas e hortaliças e a qualidade na comercialização. Faz Ciência, Francisco Beltrão, v.12, n.15, p.121-136, 2010.

ALVES, V. O.; VIEIRA, N. S.; SILVA, T. C.; FERREIRA, P. R.. O Associativismo na agricultura familiar dos estados da Bahia e Minas Gerais: potencialidades e desafios frente ao programa de aquisição de alimentos (PAA). Administração Pública e Gestão Social, Viçosa, v.3, n.1, p.66-88, 2011.
ANVISA. Agência Nacional de Vigilância Sanitária. Resolução RDC ANVISA n.352 de 23 de dezembro o de 2002. Dispõe sobre o Regulamento Técnico de Boas Práticas de Fabricação para Estabelecimentos Produtores/Industrializadores de Frutas e ou Hortaliças em Conserva e a Lista de Verificação das Boas Práticas de Fabricação para Estabelecimentos Produtores/Industrializadores de Frutas e ou Hortaliças em Conserva. Brasília: ANVISA, 2002.

ARAÚJO, S. M. M.; LEMOS, R. N. S.; QUEIROZ, M. E. R.; NUNES, G. S.. Uso de inseticidas organofosforados nos pólos de produção na ilha de São Luís (MA): condições de trabalho e contaminação de hortaliças. Pesticidas: Revista de Ecotoxicologia e Meio Ambiente, Curitiba, v.11, n.1, p.159179, 2001.

BATALHA, M. O.; IANNONI, A. P.; SILVA, A. L.; LIMA FILHO, D. O.; SCRAMIM, F. C. L.; SOUZA FILHO, H. M.; NANTES, J. F. D.; PAULILLO, L. F.; SCARPELLI, M.; AZEVEDO, P. F.; MORABITO, R.; SPROESSER, R. L.; MARTINS, R. A.; BIALOSKORSKI NETO, 
S.. Gestão Agroindustrial, São Paulo, v.1, n.3, p.636-714, 2007.

BERNADO, S.; SOARES, A. A.; MANTOVANI, E. C.. Manual de irrigação. 8 ed. Viçosa: UFV, 2006.

\section{BRASIL. Decreto n.4074 de 4 de janeiro de 2002.}

Regulamenta a Lei n.7802, de 11 de julho de 1989, que dispõe sobre a pesquisa, a experimentação, a produção, a embalagem e rotulagem, o transporte, o armazenamento, a comercialização, a propaganda comercial, a utilização, a importação, a exportação, o destino final dos resíduos e embalagens, o registro, a classificação, o controle, a inspeção e a fiscalização de agrotóxicos, seus componentes e afins, e dá outras providências. Brasília: DOU, 2002.

BRASIL. Ministério da Agricultura, Pecuária e Abastecimento. Associativismo. Brasília: MAPA, 2012.

BRASIL. Ministério da Agricultura, Pecuária e Abastecimento. Boas Práticas Agrícolas. Brasília: MAPA, 2017.

BRASIL. Portaria n.1469 de $\mathbf{2 9}$ de dezembro de $\mathbf{2 0 0 0 .}$ Estabelece os procedimentos e responsabilidades relativos ao controle e vigilância da qualidade da água para consumo humano e seu padrão de potabilidade, e dá outras providências. Brasília: DOU, 2000.

CARVALHO, D. C. M.; MONTEIRO, M. S. L.. (Des) Construção teórica da agricultura familiar. OKARA, João Pessoa, v.9, n.1, p.134-143, 2015.

CHIAVENATO, I.. Teoria geral da administração. 6 ed. Rio de Janeiro: Elsevier, 2001.

CONAB. Companhia Nacional de Abastecimento. Custos de Produção Agrícola: A metodologia da CONAB. Brasília: CONAB, 2010.

EMBRAPA. Empresa Brasileira de Pesquisa Agropecuária. Hortaliças em revista. Brasília: EMBRAPA, 2015.

EMBRAPA. Empresa Brasileira de Pesquisa Agropecuária. Irrigação e drenagem. Brasília: EMBRAPA, 2017.

EMBRAPA. Empresa Brasileira de Pesquisa Agropecuária. Manual de Boas Práticas Agrícolas e Sistema APPCC. Brasília: EMBRAPA, 2004.

FAULIN, E. J.; AZEVEDO, P. F.. Distribuição de hortaliças na agricultura familiar: uma análise das transações.
Informações Econômicas, São Paulo, v.33, n.11, p.24-37, 2003.

GARCIA FILHO, D. A.. "Análise diagnóstico de sistemas agrários": guia metodológico. Brasília: INCRA, 1999.

GRANDE, L.; LUZ, J. M. Q.; MELO, B.; LANA, R. M. Q.; CARVALHO, J. O. M.. O cultivo protegido de hortaliças em Uberlândia-MG. Horticultura Brasileira, Brasília, v.21, n.2, p.241-244, 2003.

IBGE. Instituto Brasileiro de Geografia e Estatística. Censo agropecuário 2006. Rio de Janeiro: IBGE, 2006.

IBGE. Instituto Brasileiro de Geografia e Estatística. Cidades. Disponível em: Rio de Janeiro: IBGE, 2015.

MATTOS, L. M.; MORETTI C. L.; MOURA, M. A.; MALDONADE, I. R.; SILVA, E. Y. Y.. Produção segura e rastreabilidade de hortaliças. Horticultura Brasileira Brasília, v.27 n.4, p.408-413, 2009.

NEVES, M. C. P.. Boas práticas agrícolas e a produção orgânica de frutas legumes e verduras. Seropédica: EMBRAPA, 2005

PASSOS, M. L. V.; ZAMBRZYCKI, G. C.; PEREIRA, R. S.. Balanço hídrico e classificação climática para uma determinada região de Chapadinha-Ma. Revista Brasileira de Agricultura Irrigada, Fortaleza, v.10, n.4, p.758-766, 2016.

PREZA, D. L. C.; AUGUSTO, L. G. S.. Vulnerabilidades de trabalhadores rurais frente ao uso de agrotóxicos na produção de hortaliças em região do Nordeste do Brasil. Revista Brasileira de Saúde Ocupacional, São Paulo, v.37, n.125, p.89-98, 2012.

SANTOS, M. A. T.; AREAS, M. A.; REYES, F. G.. Piretróides: uma visão geral. Alimentos e Nutrição, Araraquara, v.18, n.3, p.339-349, 2007

SEBRAE. Serviço Brasileiro de Apoio às Micro e Pequenas Empresas. Métodos de irrigação em hortaliças. Brasília: SEBRAE, 2015.

SOUSA, A. P.; VIANNA, H. A.; MINETTE, L. J.; MACHADO, C. C.. Avaliação das condições de segurança no trabalho nos setores florestais de uma instituição federal de ensino superior. Árvore, Viçosa, v.34, n.6, p.1139-1145, 2010.

A CBPC - Companhia Brasileira de Produção Científica (CNPJ: 11.221.422/0001-03) detém os direitos materiais desta publicação. Os direitos referem-se à publicação do trabalho em qualquer parte do mundo, incluindo os direitos às renovações, expansões e disseminações da contribuição, bem como outros direitos subsidiários. Todos os trabalhos publicados eletronicamente poderão posteriormente ser publicados em coletâneas impressas sob coordenação da Sustenere Publishing, da Companhia Brasileira de Produção Científica e seus parceiros autorizados. Os (as) autores (as) preservam os direitos autorais, mas não têm permissão para a publicação da contribuição em outro meio, impresso ou digital, em português ou em tradução. 